\title{
Morphological Evaluation of the Bovine Dentin prepared with High-speed Turbine or Er:YAG Laser and submitted to Different Adhesive Systems after Laser Etching
}

\author{
${ }^{1}$ Carlos Rocha Gomes Torres, ${ }^{2}$ Maria Amélia Máximo de Araujo, ${ }^{3}$ Simone Cristina Teixeira \\ ${ }^{1}$ Maria Filomena Rocha Lima Huhtala \\ ${ }^{1}$ Assistant Professor, Department of Restorative Dentistry, São José dos Campos School of Dentistry, UNESP, Brazil \\ ${ }^{2}$ Chairman and Professor, Department of Restorative Dentistry, São José dos Campos School of Dentistry, UNESP, Brazil \\ ${ }^{3}$ Assistant Professor, Department of Social Science and Pediatric Dentistry, São José dos Campos School of Dentistry, UNESP, Brazil
}

Correspondence: Carlos Rocha Gomes Torres, Av Eng Francisco José Longo, 777, Jardim São Dimas, São José dos Campos São Paulo, CEP 12245-000, Brazil, e-mail: carlosrgt@ fosjc.unesp.br

\begin{abstract}
This study evaluated the effect of the Er:YAG laser at different settings on the surface of bovine dentin as well as adhesive systems. A total of 21 bovine teeth had their apexes embedded in chemically activated acrylic resin to allow sectioning of a dentin slice parallel to the buccal aspect of each tooth. Thus, group A (12 slices), prepared with the high-speed turbine, being four for analysis of the dentin surface, four for analysis of the interface and four for analysis of resin tags. Group B ( 9 slices) prepared with the Er:YAG laser, being three for analysis of the surface, three for analysis of the interface and three for analysis of resin tags. Each slice received a different treatment: etching with phosphoric acid, Er:YAG laser $(60 \mathrm{~mJ} / 10 \mathrm{~Hz}$ ), conventional adhesive Excite (Vivadent) and self-etching adhesive One-Up Bond F (Tokuyama). For analysis of the interface, all slices were fractured for exposure of the resin/dentin bond. All slices were processed to allow evaluation by scanning electron microscopy. The results revealed that the Er:YAG laser employed both for preparation and dentin etching removed the smear layer, opened the dentinal tubules and yielded surface cracks; there was formation of a large amount and deep tags in the study groups, except for the slice prepared with diamond bur at high-speed and self-etching adhesive systems; the interfaces revealed adequate adaptation of the adhesive system/composite resin to the dentin, with little evidence of hybrid layer; also, the slice prepared with diamond bur, etched with phosphoric acid and receiving the Excite adhesive system displayed a porous hybrid layer.
\end{abstract}

Keywords: Laser Er:YAG, Dentin adhesives, Microleakage.

\section{INTRODUCTION}

The great current concern is the search for a material that may provide effective sealing and adhesion to the tooth substrate, which may be affected by somefactors, as the presence of smear layer, formation of hybrid layer, the tooth substrate itself or characteristics of the adhesive system employed. ${ }^{1}$

Dentistry has also been searching for alternative equipments to the high-speed turbines with the same cutting ability, yet which may provide more comfort to the patients; one such equipment is the Er:Y A G laser.

Investigations have demonstrated that modifications in the parameters of laser may lead to differentiated morphological alterations in the tooth substrate and interfere with the effectiveness of adhesion. ${ }^{2-7}$

Even though the Er:Y A G laser has been demonstrated to be effective for removal of dental tissue and provides comfort to the patient, ${ }^{5}$ the performance of adhesive materials on the tooth surfaces provided by utilization of this appliance is not yet well established, since these surfaces are different from those produced by rotary instruments on which these materials are commonly employed, and evaluation of the bonding interface reveals contradictory outcomes. ${ }^{5,8,9}$

The adhesive materials are able to interact with a surface covered by smear layer, resulting from the action of diamond burs or tungsten burs employed with high-speed turbines. W ith the utilization of laser, there will bea new dentin substrate, which brings about doubts on its ability to interact with the existing adhesive materials.

Therefore, the development of new equipments for cavity preparation and the need to know the interaction between resulting substrates and the adhesive systems encouraged accomplishment of the present study.

\section{MATERIALS AND METHODS}

\section{Evaluation by Scanning Electron Microscopy}

Scanning electron microscopy (SEM) was employed for evaluation of the effects of instruments, cavity preparation, dentin surface treatment and adhesive systems. 
For that purpose, 21 extracted teeth were selected and cleaned; their pulp tissue was removed and their apical third was embedded in chemically activated acrylic resin. A dentin slice of nearly $1 \mathrm{~mm}$ thickness was achieved parallel to the buccal aspect of all teeth in the sample, and were properly identified and divided into two groups: group A with 12 slices, and group $B$ with nine slices (Figs 1 and 2).

In group A, 12 slices were superficially ground with a diamond bur no. 1092 at high-speed (K G Sorensen). The four first slices were submitted to analysis of the dentin surface, other four were submitted to analysis of the interface, and other four were submitted to analysis of the resin tags.

One sl ice submitted to analysis of the surface did not receive any additional treatment to allow observation only of the effect of diamond bur. In the second slice, the dentin was etched with Er:YA G laser $(60 \mathrm{~mJ}$ and $10 \mathrm{~Hz})$. The third slice was etched with $37 \%$ phosphoric acid for 15 seconds, thoroughly washed

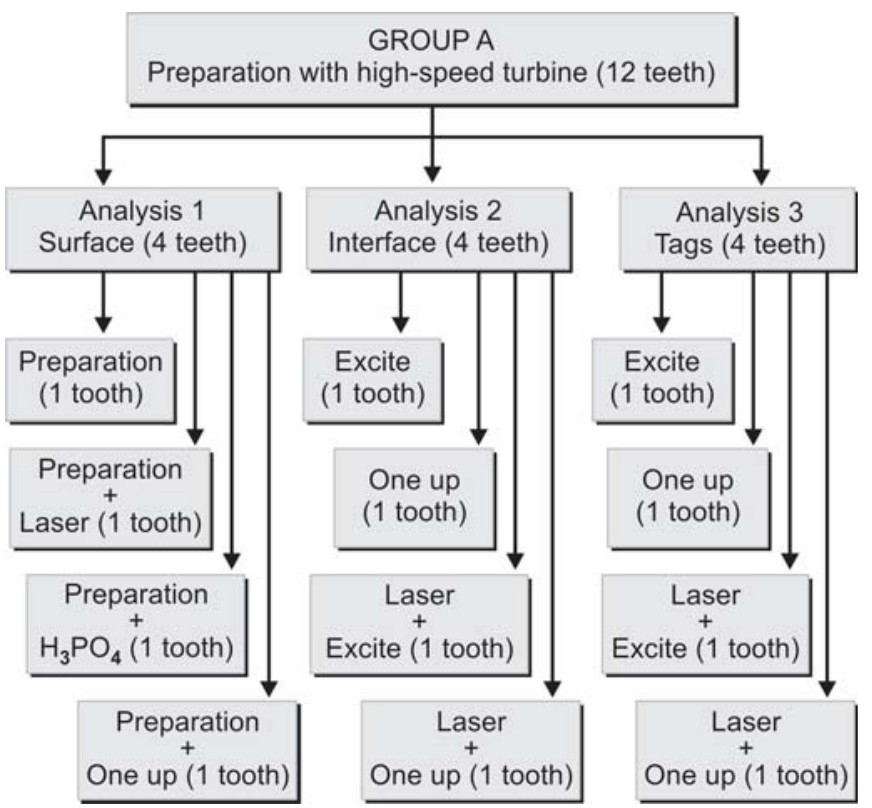

Fig. 1: Scheme of dentin treatment for group $A$

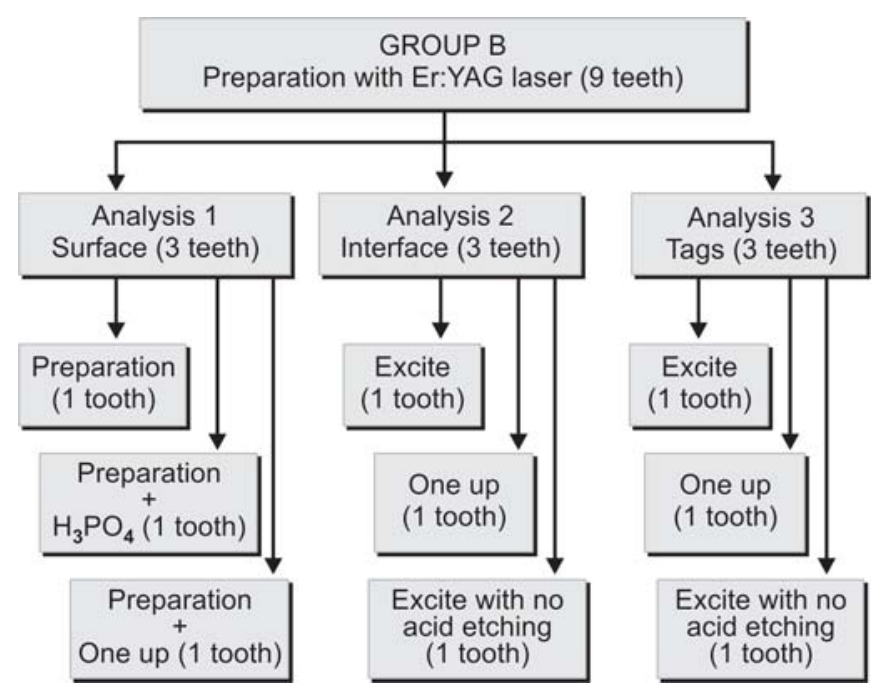

Fig. 2: Scheme of dentin treatment for group B with water jets and kept in distilled water until processing for $S E M$. The fourth slice received application of $O$ ne $U p$ B ond $F$ for 20 seconds, being thoroughly washed with water and immersed in acetone for 5 minutes.

With regard to the slices submitted to analysis of the interface, the first received the adhesive excite (V ivadent) and composite resin, the second received the adhesive One-Up Bond $F$ (Tokuyama) and composite resin (both applied as recommended by the manufacturers), the third slice received application of the Er:Y A G laser at $60 \mathrm{~mJ}$ and $10 \mathrm{~Hz}$ followed by application of Excite without acid etching and composite resin, and the fourth slice received the Er:Y A G Iaser $(60 \mathrm{~m})$ and $10 \mathrm{~Hz}$ ) followed by application of the One-Up B ond $F$ adhesive and composite resin.

The other four slices submitted to analysis of the resin tags, were processed as the slices for interface analysis with different processing for SEM.

The slices for surface and interface analysis were immersed in $2.5 \%$ glutaral dehyde in $0.1 \mathrm{M}$ of sodium cacodylate at 4 으 for 12 hours, then washed in a buffer solution of $0.2 \mathrm{M}$ sodium cacodylate solution for 1 hour with three changes of solution, followed by immersion in distilled water for 1 minute. They were then dehydrated in increasing concentrations of ethanol ( $25 \%$ for 20 mins, $50 \%$ for 20 mins, $75 \%$ for 20 mins, $95 \%$ for 30 mins and $100 \%$ for 60 mins). A fterwards, all specimens were dried by immersion in hexamethyldisilazane for 10 minutes, placed on an absorbent filter paper under a glass dome and allowed to dry at room temperature. ${ }^{10}$

The slices for interface analysis were fractured for exposure of the resin/dentin bond. Processing of the slices for analysis of the resin tags comprised immersion in 37\% hydrochloric acid for 2 days, washing in water and immersion in 10\% sodium hypochlorite for 3 days, for maintenance only of the resin material. They were then washed in tap water and immersed in absolute ethanol for 10 minutes.

The 12 slices were mounted on aluminum stubs and submitted to evaporation of gold by the sputtering method on the Desk II machine (D enton V acuum) for 2 minutes; then, all specimens were observed under a scanning electron microscope (J M S-5310 - Jeol). Figures 1 and 2 reveal the study design followed for study groups $A$ and $B$.

In group $B$, with nine slices, the surfaces received application of the Er:Y A G laser at $400 \mathrm{~mJ}$ of pulse energy and $4 \mathrm{~Hz}$ of frequency. This group of specimens was not submitted to application of laser at $60 \mathrm{~mJ} / 10 \mathrm{~Hz}$, and evaluation of the walls interface and tags was conducted with variations in the adhesive system and utilization or not of acid etching of the surfaces.

All steps were similar to those described for group A.

\section{RESULTS}

Results are as shown in Figures 3 to 13D. 
Morphological Evaluation of the Bovine Dentin prepared with High-speed Turbine or Er:YAG Laser

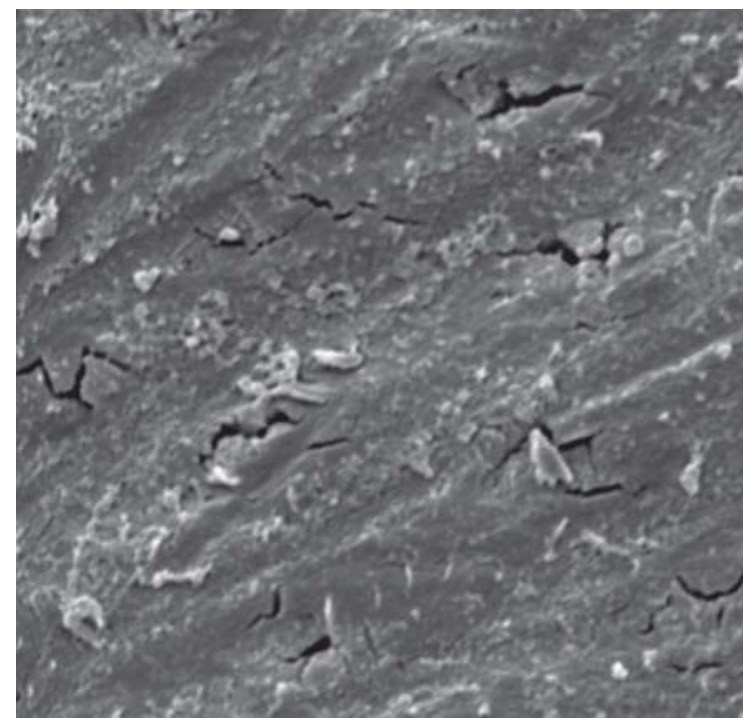

Fig. 3: Preparation with diamond burs laser, wall obliterated by smear layer (5,000x magnification)

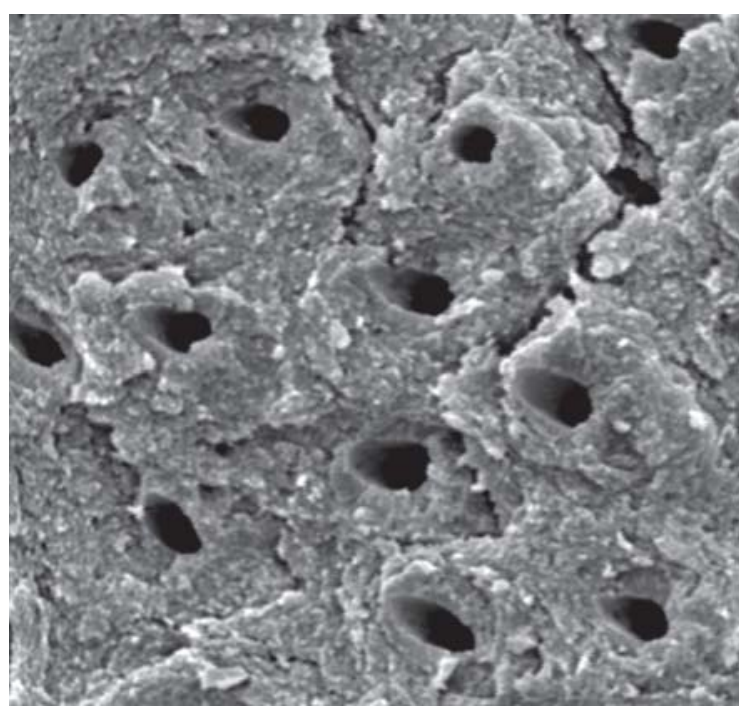

Fig. 4: Preparation with Er:YAG, absence of smear layer (5,000x magnification)

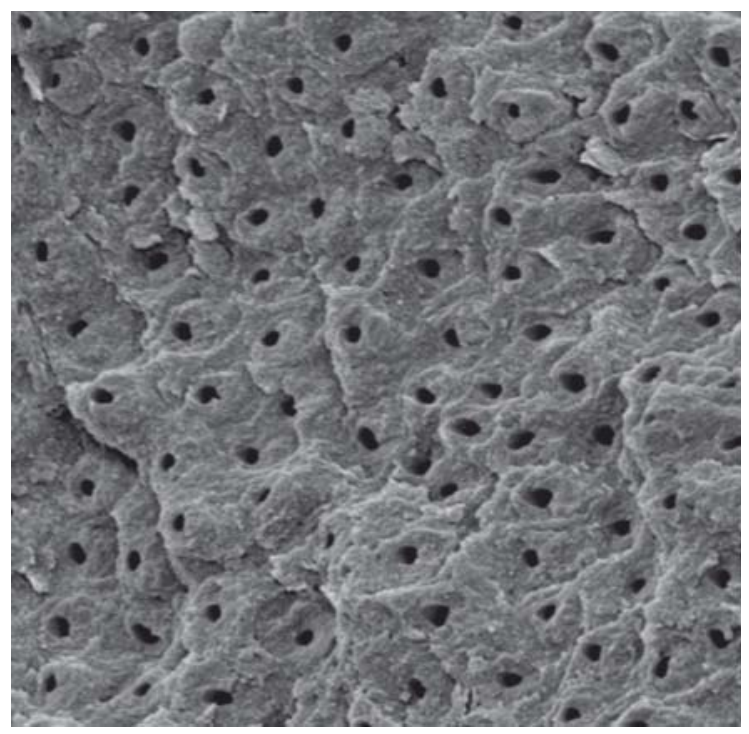

Fig. 5: Preparation with diamond bur application of laser at $60 \mathrm{~mJ} / 10 \mathrm{~Hz}$, removal of smear layer (2,000x magnification)

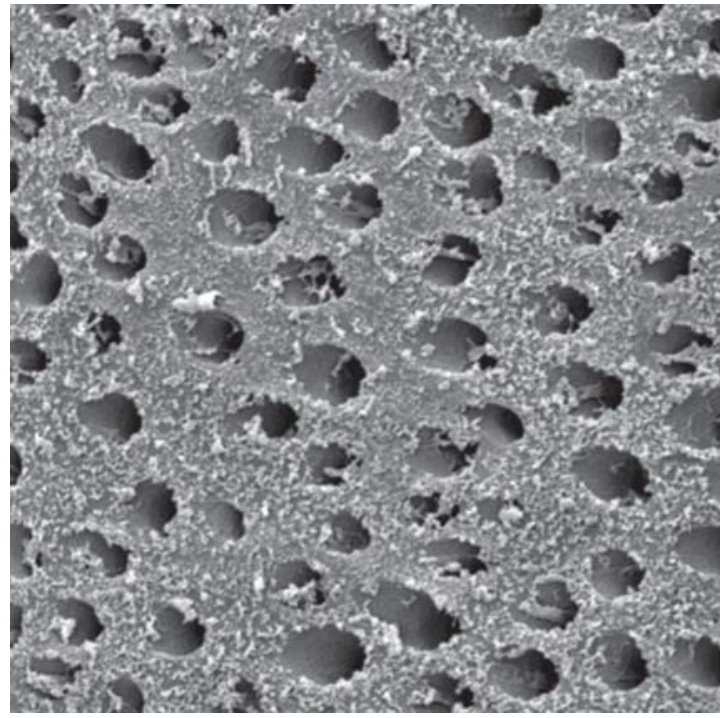

Fig. 6: Preparation with diamond bur application of phosphoric acid and removal of smear layer (2,000x magnification)

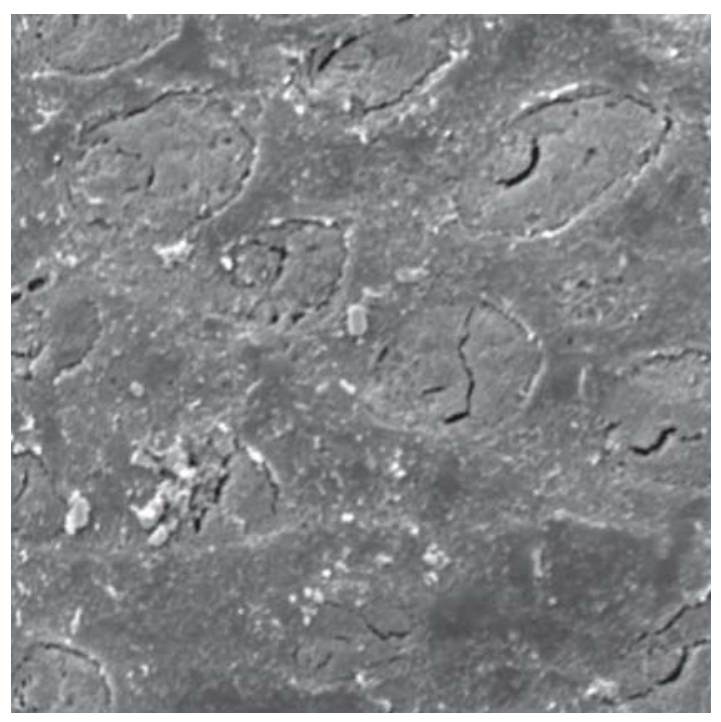

Fig. 7: Preparation with diamond burs and self-etching adhesive system, smear plugs sealing the opening of dentinal tubules $(5,000 \times$ magnification)

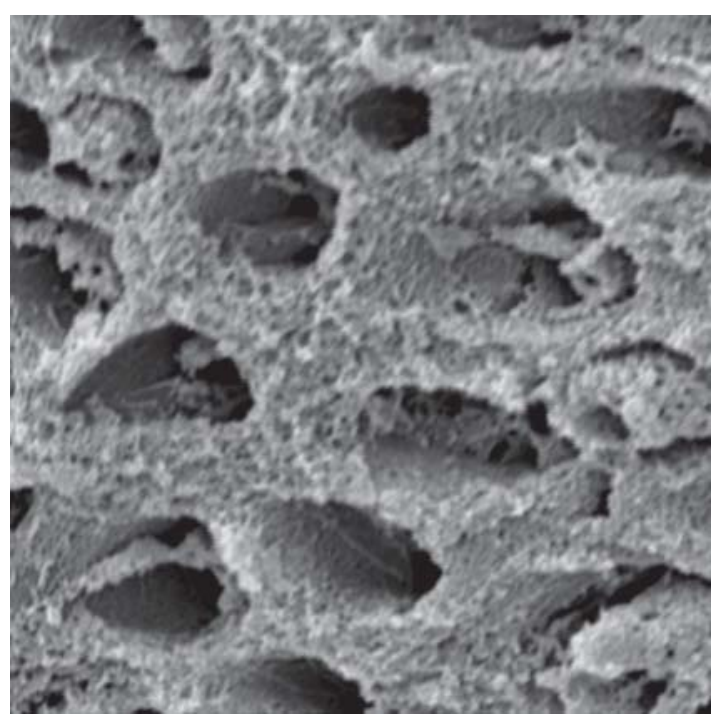

Fig. 8: Preparation with laser and etching with phosphoric acid, increase in surface porosities (5,000x magnification) 


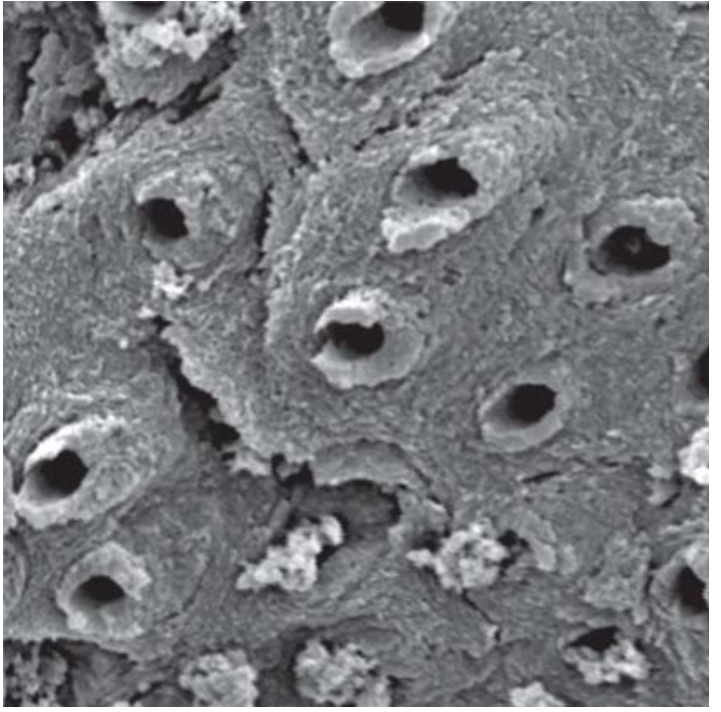

Fig. 9: Preparation with laser, the peritubular dentin was not removed (5,000x magnification)

\section{DISCUSSION}

Utilization of the Er:YAG is able to provide acceptable microretention for adhesive materials, roughening the dentin as the acid etching. 2,5,7,9,11

W hen the dentin was prepared with high-speed turbines and then submitted to laser etching with Er:YAG at low energy parameters $(60 \mathrm{~mJ} / 10 \mathrm{~Hz})$, there was also removal of the smear layer and opening of dentinal tubules, corroborating the findings of other studies. 2,3,4,6,12

This study revealed that combination of the self-etching adhesive system and the smear layer yielded a more uniform surface with presence of smear plugs partially sealing the openings of the dentinal tubules.

When etching with phosphoric acid was performed on the dentin prepared with diamond burs, there was removal of smear layer and opening of dentinal tubules similar to the effect yielded by laser, for both the preparation $(400 \mathrm{~mJ})$ and etching $(60 \mathrm{~mJ})$.
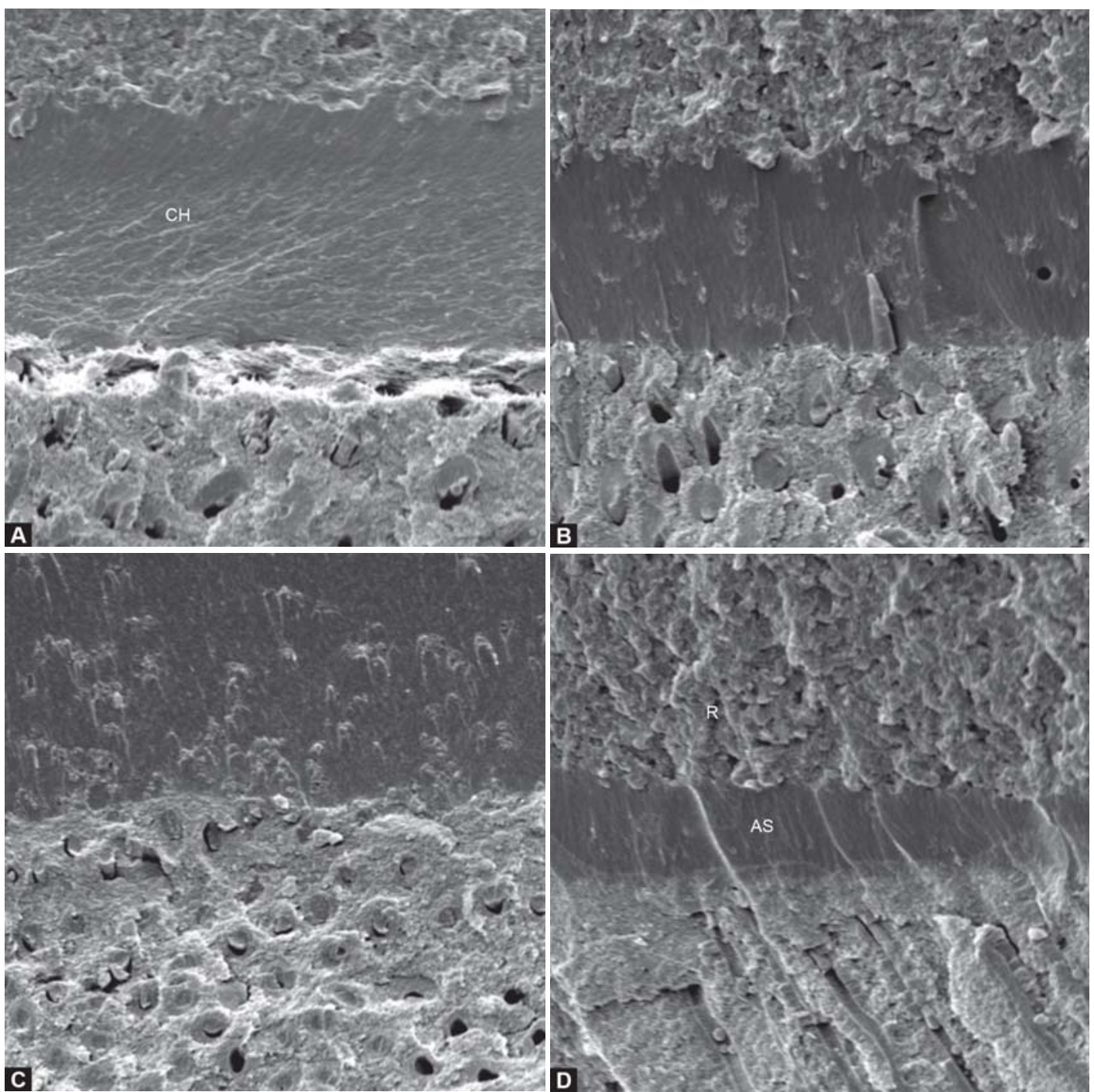

Figs $10 \mathrm{~A}$ to $\mathrm{D}$ : (A) Cavity preparation with diamond bur, etching and adhesive system, porous hybrid layer-2,000x magnification (R - resin, AS - adhesive system, $\mathrm{CH}$ - hybrid layer); (B) cavity preparation with diamond bur and self-etching adhesive, absence of hybrid layer-2,000x magnification; (C) surface prepared with laser $(60 \mathrm{~mJ}$ and $10 \mathrm{~Hz})$ and self-etching adhesive, demonstrating quality of the interface-2,000x magnification; and (D) utilization of laser for surface preparation allowed improved adaptation between adhesive and composite resin-2,000x magnification 
Morphological Evaluation of the Bovine Dentin prepared with High-speed Turbine or Er:YAG Laser

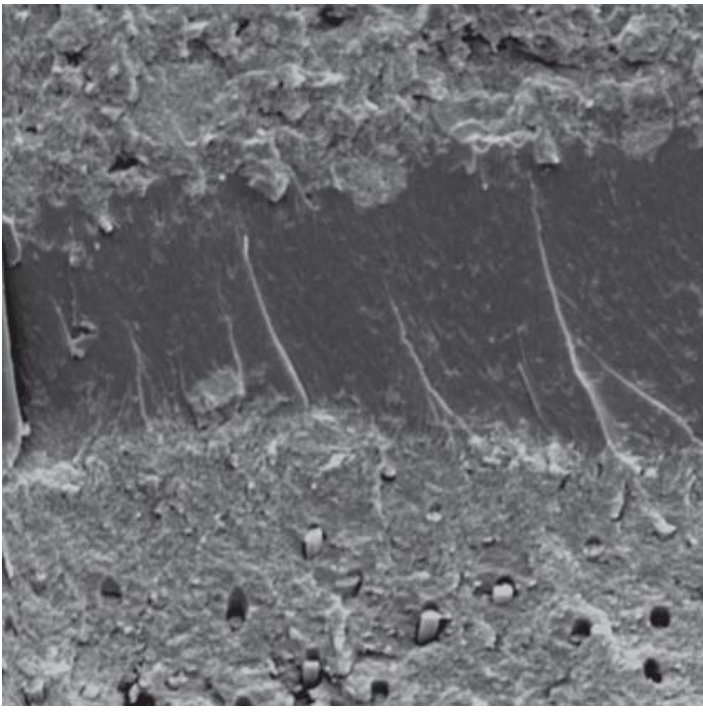

Fig. 11: Cavity preparation with laser and acid etching adhesive, suggesting evidence of hybrid layer (2,000x magnification)

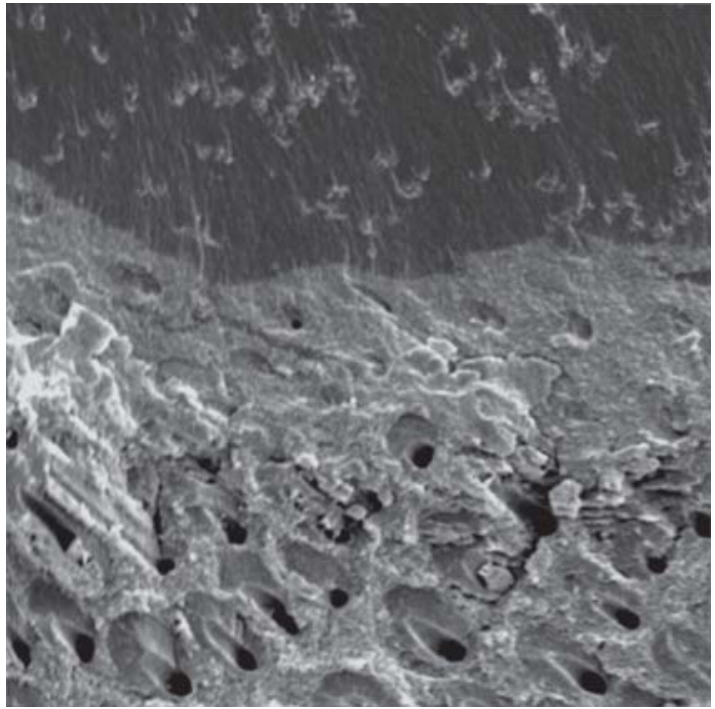

Fig. 12: Cavity preparation with self-etching adhesive, presence of hybrid layer (2,000x magnification)
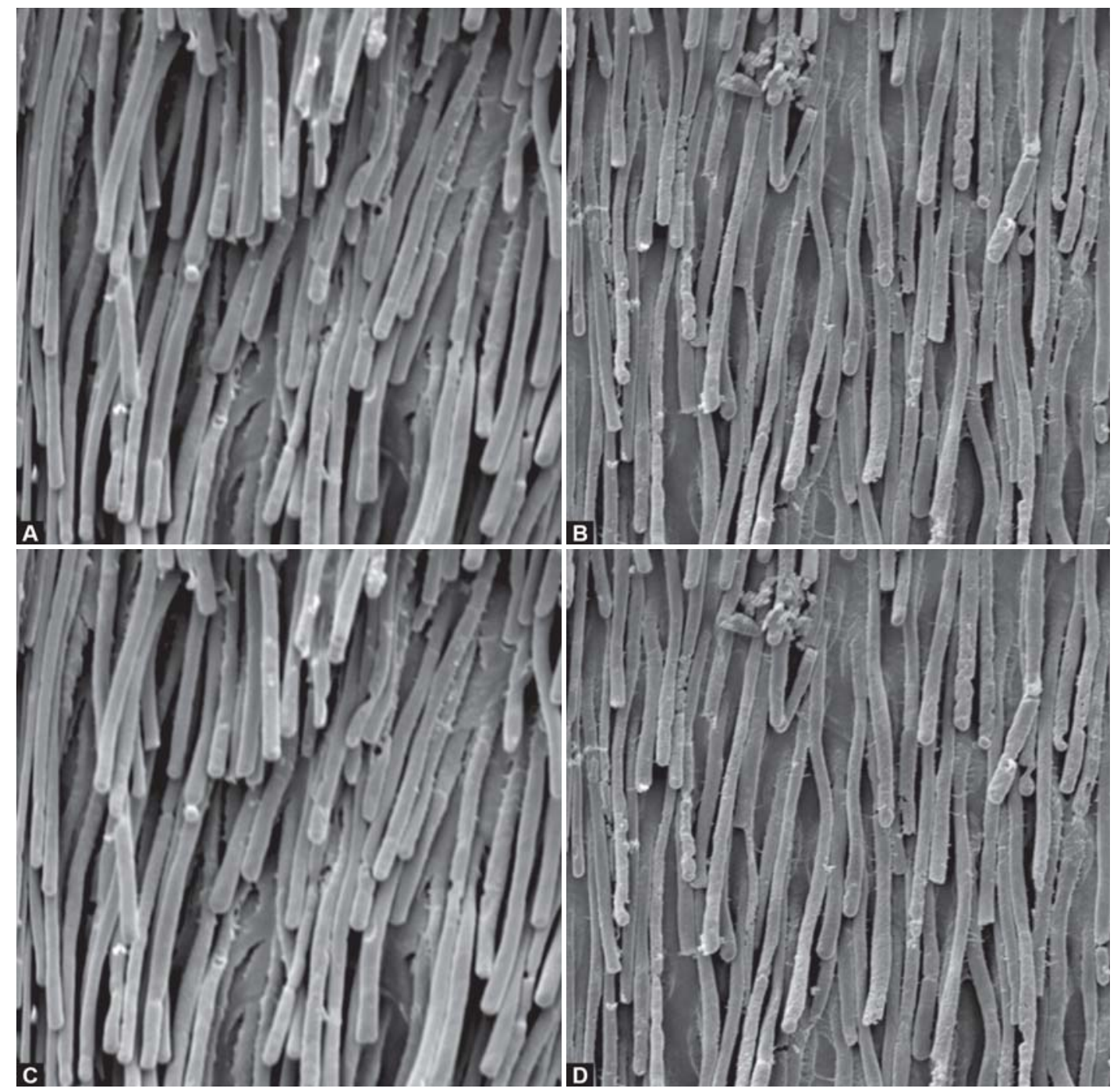

Figs 13A to D: (A) Preparation with high-speed turbine and diamond bur, surface etching with laser at $60 \mathrm{~mJ} / 10 \mathrm{~Hz}$ and adhesive system Excite. Penetration of adhesive monomers with formation of a great amount of resin tags-2,000x magnification $(B+L+E x)$; $(B)$ preparation with Er:YAG laser $(400 \mathrm{~mJ} / 4 \mathrm{~Hz})$, acid etching and adhesive system Excite-2,000x magnification, revealing extensive formation of resin tags $(\mathrm{L}+\mathrm{Ac}$ + Ex); (C) preparation with high-speed turbine and diamond bur, surface etching with $60 \mathrm{~mJ} / 10 \mathrm{~Hz}$ laser and adhesive system One Up (5,000x magnification). Note the network of deep resin tags $(B+L+U p)$; (D) preparation performed with diamond bur at high-speed and self-etching adhesive system One Up. The 2,000x magnification reveals scarce and predominantly shallow tags 
A pplication of phosphoric acid to the surface prepared with laser $(400 \mathrm{~mJ})$ yielded an increase in surface porosity, by dissolution of the peritubular dentin and exposure of collagen fibers. ${ }^{13,14}$

The self-etching adhesive system applied to the laser-treated surface also increased the porosity and led to partial opening of the tubules, yet with preservation of the peritubular dentin. This was al so observed by B ertrand et al ${ }^{15}$ (2004) and D ostálová et al ${ }^{16}$ (1998), who established a classification for self-etching systems based on the degree of dissolution of the smear layer. They observed that in some commercial brands, the smear layer and smear plugs were contained in the hybridization process.

W ith regard to utilization of laser to etch $(60 \mathrm{~mJ})$ the dentin prepared with diamond burs without acid etching, no hybrid layer was observed under SEM, yet there was a remarkable improvement in adaptation of the composite resin, suggesting that opening of the dentinal tubules may have improved the adaptation due to formation of resin tags.

These results are in agreement with Freitas et $\mathrm{al}^{3}$ (2007), and $\mathrm{G}$ iachetti et $\mathrm{al}^{14}$ (2004), that also observed the presence of hybrid layer and dentinal tubules impregnated by resin, under SEM .

The dentin prepared with laser $(400 \mathrm{~mJ})$ and etched with $37 \%$ phosphoric acid, followed by application of the conventional adhesive Excite, demonstrated satisfactory interfacial adaptation and little evidence of hybrid layer. On the other hand, for the self-etching adhesive system, the hybrid layer was homogeneous and uniform with absence of porosity.

The surface of slices submitted to analysis of resin tags revealed that only the dentin prepared with diamond burs and submitted to the self-etching adhesive system $(B+U P)$ exhibited scarce and shallow tags, whereas the other dentin surfaces displayed long and abundant resin tags. These results suggest similarity between utilization of phosphoric acid and laser for removal of smear layer and opening of dentinal tubules, corroborating the findings of de Carvalho et $\mathrm{al}^{4}$ (2007).

A nother interesting observation is related to the network or anastomosis of resin tags when the laser and self-etching adhesive were employed. This characteristic was al so observed by B ertrand et al ${ }^{15}$ (2004), who yet associated laser irradiation to acid etching of the surface. Besides hybridization, the penetration of resin monomer into the dentinal tubules forming the "resin tags" only contributes for adhesion, if there is proper hybridization to the lateral walls of the dentinal tubules. ${ }^{1,3,14}$

N onetheless, Ceballos et al ${ }^{17}$ (2001) considered that there are differences in the morphology of dentinal tubules after application of phosphoric acid for etching or laser irradiation. In the case of acid etching, the peritubular dentin is removed, yielding a funnel-shaped opening of the tubules, and this morphology may contribute to displace the composite resin far from the tubule walls during the polymerization shrinkage. On the other hand, irradiation with the Er:Y AG laser does not produce demineralization of the peritubular dentin and yields cone-shaped opening of the tubules with smaller diameter, therefore reducing the effect of polymerization shrinkage and improving the adhesion. This morphology was not evident in the present study upon comparison of tags, yet is in agreement with Figure 9, which displays the non-demineralized peritubular dentin. The results achieved demonstrate that there are still some aspects to elucidate as to utilization of the Er:YAG Iaser associated to the commercially available adhesive systems, and thus further investigations on this issue are warranted.

\section{CONCLUSION}

The Er:Y A G laser, used for both cavity preparation and etching of the dentin surface, removed the smear layer, opened the dentinal tubules and yielded surface cracks.

There was similar formation of tags in large amount and depth in the study groups, except for the dentin surface prepared with diamond bur at high-speed turbine followed by self-etching adhesive system; the interfaces demonstrated proper adaptation of the composite resin with little evidence of hybrid layer; however, the surface receiving $(B+A c+E x)$ revealed presence of a porous hybrid layer.

\section{REFERENCES}

1. Perdigão J. New developments in dental adhesion. Dent Clin North A m A pr 2007;51(2):333-57.

2. Kohara EK, Hossain M, K imura $Y, M$ atsumoto $K$, Inoue $M$, Sasa R. M orphological and microleakage studies of the cavities prepared by Er:Y A G laser irradiation in primary teeth. J Clin Laser $M$ ed and Surg 2002;20(3):141-47.

3. Freitas PM, Navarro RS, Barros J A, D e Paula Eduardo C. The use of Er:Y A G laser for cavity preparation: A $\cap$ SEM evaluation. Microsc Res Tech Sep 2007;70(9):803-08.

4. De Carvalho RC, De Freitas PM , Otsuki M, De Eduardo CP, Tagami J. M icro-shear bond strength of Er:Y A G-laser-treated dentin. Lasers M ed Sci M ay 4, 2007 [E pub ahead of print].

5. Corona SAM, Borsatto M C, Pécora JD, DE SÁ Rocha Ras, Ramos TS, Dibb R GP. A ssessing microl eakage of different class $\mathrm{V}$ restorations after Er:Y A G laser and bur preparation. J Oral Rehabil 2003;30:1008-14

6. Cecchini RC, Zezell DM, Oliveira E DE, Freitas $P M D E$, Eduardo CDE P. Effect of Er:YAG laser on enamel acid resistance: M orphological and atomic spectrometry analysis. Lasers Surg M ed Dec 2005;37(5):366-72.

7. Delme KI, Deman PJ, DE M oor RJ. M icroleakage of class V resin composite restorations after conventional and $\mathrm{Er}: Y \mathrm{~A} \mathrm{G}$ laser preparation. J Oral Rehabil 2005;32(9):676-85.

8. Chinelatti MA, Ramos RP, Chimello DT, Corona SA, Pécora JD, Dibb RG. Influence of Er:Y A G laser on cavity preparation and surface treatment in microleakage of composite resin restorations. Photomed Laser Surg 2006;24(2):214-18.

9. Bertrand $M F$, Semez G, Leforestier E, M uller-Bolla $M$, Nammour S, RoccaJ P. Er:Y A G laser preparation and composite resin bonding with a single-component adhesive system: Relationship between shear bond strength and microleakage. Lasers Sugr M ed 2006;38(6):615-23.

10. Perdigão J , L ambrechts $P, V$ an $M$ eerbeek $B, V$ anherle $G$, L opes $A L$. Field emission SEM comparison of four postfixation drying techniques for human dentin. J Biomed Mater Res 1995;29:1111-20 
Morphological Evaluation of the Bovine Dentin prepared with High-speed Turbine or Er:YAG Laser

11. V isuri SR, Gilbert JL, W right DD, W igdor HA, Walsh JR, JT. Shear strengths of composite bonded to Er:Y A G laser prepared dentin. J Dent Res Dec J an 1996;75:599-605.

12. A ranha $A C$, Turbino $M L$, Powell $G L$, Eduardo $C P$. A ssessing microleakage of class $\mathrm{V}$ composite restorations after Er:YAG Iaser and bur preparation. Lasers Surg M ed 2005;37(2): 172-77.

13. Groth $E B, M$ ercer $C E$, A nderson P. M icrotomographic analysis of subsurface enamel and dentine following Er:Y A G laser and acid etching. Eur J Prosthod Restor Dent 2001;9(2):73-79.

14. Giachetti L, Scaminaci Russo D, Scarpelli F, V itale M. SEM analysis of dentin treated with the Er:Y A G Iaser: A pilot study of the consequences resulting from laser use on adhesion mechanisms. J Clin Laser M ed Surg Feb 2004;22(1):35-41.

15. B ertrand M F, Hessleyer D, M uller-B olla M, N ammour S, Rocca JP. Scanning electron microscopic evaluation of resin-dentin interface after Er:Y A G laser preparation. Lasers Surg Med 2004;35(1):51-57.

16. Dostálová $T$, J elinkova $H, K$ ucerova $H, K$ rejsa 0 , Hamal K, Kubelka J, Prochazka S. Noncontact Er:Y A G laser ablation: Clinical evaluation. J Clin L aser M ed Surg 1998;16(5):273-82.

17. Ceballos L, O sorio R, Toledano M, M arshall GW. M icroleakage of composite restorations after acid or Er-Y A G laser cavity treatments. D ental M aterials 2001;17(4):340-46. 